\title{
TEMA EM DESTAQUE \\ A TRANSMISSÃO CULTURAL ASSEDIADA: \\ METAMORFOSES DA CULTURA \\ COMUM NA ESCOLA
}

\author{
INÉS DUSSEL \\ Cooordenadora da Área Educación, Facultad Latinoamericana \\ de Ciencias Sociales - Argentina \\ idussel@flacso.org.ar
}

Tradução: Neide Luzia de Rezende

\section{RESUMO}

Neste artigo, gostaríamos de propor algumas reflexões em torno do que se percebe como crise da transmissão escolar. Mais especificamente, interessa-nos o que decorre da discussão sobre a cultura comum que a escola deve transmitir, tendo em vista que essa instituição está voltada para a formação do núcleo de referências comuns que permite ao aluno se integrar à sociedade nacional e se converter em cidadão. Hoje, tanto a ideia de "cultura comum" como a própria noção de tradição e reprodução cultural parecem sob assédio. Em primeiro lugar, esse assédio tem a ver com o declínio das humanidades modernas como centro de referência da cultura comum - um declínio que já tem mais de um século. Em segundo lugar, está ocorrendo uma transformação profunda da ideia de tradição e reprodução cultural, bem como das formas com que estas se realizam. Ambos os elementos são discutidos no artigo. Por último, para retomar a ideia de transmissão da cultura comum na escola, sugerem-se alguns critérios que levem em conta os questionamentos e desafios da construção de uma tradição nas presentes condições. ESCOLA - CIDADANIA - CURRÍCULO - CULTURA

\section{ABSTRACT}

CULTURAL TRANSMISSION UNDER HARASSMENT: AVATARS OF COMMON CULTURE IN SCHOOL. In this article, I advance some arguments about what is perceived as the crisis of the act of transmitting or passing over culture to new generations. More specifically, I am interested in understanding what is built into the discussion of what a common culture is, and what role schools play in their formation. Schools were institutions that were conceived for producing a core of common references that allowed people to be included in the national society and turn into citizens.

Este artigo foi publicado originalmente em Propuesta Educativa, Buenos Aires, n. 28, p. 19-27, nov. 2007: "La transmisión cultural asediada: los avatares de la cultura común em la escuela". 
Today, both the idea of a 'common culture' and the notion of tradition and cultural reproduction appear to be under siege. First, this siege is linked to the decline of modern humanities as the reference centre for common culture - a decline that has been taking place for over a century. Second, what is taking place is a profound transformation of the ideas of tradition and cultural reproduction, and of the ways in which they are performed. Both elements are discussed in this article. Finally, I suggest some criteria to rethink the passing over of a cultural tradition in schools, taking into account the challenges and questions that have been posed to the construction of a tradition in present conditions

SCHOOLING - CITIZENSHIP - CURRICULUM - CULTURE

que foi feito do ideal de transmitir a cultura, e, mais especificamente, uma "cultura comum" a todos os cidadãos através da escola? Neste artigo gostaríamos de propor algumas reflexões em torno daquilo que se percebe como crise da transmissão escolar, buscando entender as formas com que hoje se apresenta o problema, além de sugerir alguns critérios para retomar a ideia de transmissão do comum.

O cerco à transmissão cultural que a escola realiza tem ao menos dois componentes fortes: o declínio das humanidades modernas e a crise da ideia de reprodução cultural.

O primeiro elemento tem a ver com o declínio do ideal humanista como eixo para a ação da escola, concebida como a via para a realização pessoal e para a ascensão social. A cultura comum esteve, ao menos para boa parte de nossos países, definida por um núcleo de humanidades modernas que estruturavam saberes, disposições e sensibilidades a serem passadas ou legadas às novas gerações. Lugar de privilégio, símbolo de distinção, as humanidades foram as que ofereceram um núcleo de referências comuns que permitiam às pessoas sentir-se parte de alguma coisa comum, de uma vida comunitária - com suas hierarquias, inclusões e exclusões... mas comum enfim.

No entanto, a legitimidade das humanidades hoje está declinando. São muitos os que reclamam que a escola não faz o que deveria, ou seja, ensinar para a vida ou para o trabalho, adequar-se aos novos tempos ou renovar sua proposta disciplinar. Da perspectiva das ciências sociais, há décadas se aponta o caráter de "invenção" da tradição proposta pela escola, sua seleção arbitrária da cultura e seu viés político e ideológico (Hobsbawm, Ranger, 1983; Williams, 1956; Bourdieu, Passeron, 1980, entre muitos outros). Provavelmente as duas impugnações mais fortes provenham hoje das críticas "multiculturais" (culturas 
majoritárias ou minoritárias que estavam excluídas do cânone tradicional) e das posições "neotecnológicas" (as novas tecnologias da informação e comunicação, que propõem outros saberes e outras formas de transmissão). As pedagogias da moda são diferentes versões do construtivismo que, em suas modalidades mais esquemáticas e pobres, comparam a transmissão do docente à lição magistral - e portanto a rechaçam - e creem que a "origem" do currículo está na psicologia infantil, algo que Dewey já discutia em "A criança e o currículo", em 1902 (Dewey, 1967). As críticas ao currículo humanista se fundamentam em três fortes exclusões que estavam em sua base: das culturas populares, da cultura contemporânea (sobretudo dos produtos da indústria cultural de massa) e da "voz" das crianças e dos adolescentes'. Como assinala George Steiner, essas críticas podem ser lidas como uma espécie de "grito de guerra", de "contra-ataque aos privilégios dos letrados", porque desses privilégios "foram excluídos centenas de milhões de seres humanos..." (Steiner, Ladjali, 2005, p. I06).

Carlos Monsiváis dedica um lúcido ensaio a essa discussão sobre qual é a cultura comum hoje, e se pergunta:

Em que momento e por que motivo a leitura e a cultura definidas classicamente (artes, música, teatro, cinema de qualidade) passam a ser algo que se envia à zona do tempo livre, enquanto que os meios e a indústria de entretenimento são para muitos 'a realidade'. E uma grande interrogação: quando se perde, definitivamente, a causa das humanidades como formação central? (Monsiváis, 2007, p.57)

\section{E Monsiváis responde:}

Expulsa-se o humanismo definitivamente do currículo educativo na década de 1970 ao se encarregar a iconosfera (o império das imagens) de formação das novas gerações. Não se vê sentido no brilhantismo verbal, e cada vez há menos gente capaz de senti-lo e admirá-lo. [...] O lugar antes central da literatura é

I. Em outro texto (Dussel, 1997), discuto a associação entre currículo humanista e formação e inclusão na vida democrática, que continua sendo central para a escola secundária, pelo menos na América do Sul. Essa associação levou à exclusão de saberes vinculados ao trabalho, à cultura contemporânea, às culturas locais e também a uma marginalização da "voz adolescente" (sabendo que essa voz não é monolíngue nem "autêntica"). 
ocupado pelas imagens, de modo que o "tempo livre" da sociedade vem a ser o que resta depois de ver partidas de futebol, telenovelas, reality shows, séries televisivas, filmes, o que não é "tempo livre" mas "obrigação urbana". (Monsiváis, 2007, p.59-60).

Sem dúvida, o que está sucedendo com a amplíssima difusão das novas tecnologias e sobretudo da televisão modifica profundamente o panorama da cultura comum e de nossas ideias sobre o que se deve transmitir. É preciso recordar, no entanto, que essa crítica às humanidades é mais antiga do que os 30 ou 40 anos que lhes outorgamos, e que talvez a crítica ao núcleo humanista escolar seja mais a consequência da extensão dos programas da democratização da cultura e da democratização escolar do que sua antagonista. No fim das contas, foi no regime de fazer-se mais e mais popular, mais e mais inclusiva, que a escola foi adotando formas e saberes do entorno e das famílias, a ponto da demanda para que ela se tornasse receptiva e hospitaleira se instalasse no centro de seu ideário (Hunter, 1998). Por sua vez, desde o escolanovismo já estavam presentes as críticas à transmissão da tradição. Uma pedagoga argentina, Natalia Fattore, destaca em texto recente que: "O progresso de uma pedagogia "sem tradição" foi o ideal a ser alcançado de todo progressivismo pedagógico. [Porém] ...o "novo", longe de nos liberar das coações da tradição, coloca-nos diante de novos riscos e perigos" (Fattore, 2007, p.29).

Para rastrear a história das críticas ao currículo humanista, pode-se observar, por exemplo, as opiniões do jovem Walter Benjamin, a quem dificilmente se poderia acusar de anti-humanista ou de anti-intelectual. Em um texto publicado em 1912 numa revista estudantil ("La reforma escolar, um movimiento cultural"), em plena efervescência da reforma escolanovista, Walter Benjamin advertia que a escola é a depositária da tradição cultural. Dizia na ocasião que "a escola é a instituição que custodia e apresenta à humanidade suas aquisições" (Benjamin, 2007, p. I6). Essa ideia de custódia, arcontes-guardião da memória, é uma noção poderosa que estruturou a ação de muitos educadores, a ponto de convertê-los em vigias ou carcereiros do saber - quase como o bibliotecário de $O$ nome da rosa, o romance de Umberto Eco (1982)².

2. É interessante vincular essa ideia de Arcontes da memória com a ideia de arquivo, que está associada à noção daquilo que se conserva de uma tradição cultural. $\bigcirc$ termo "arquivo, diz 
Mas Benjamin não ignorava, e tampouco queria deixar de assinalar ao movimento estudantil de início do século $X X$, que a escola não é só passado. " $O$ que a escola faz é mérito do passado, ainda que às vezes de passado recente. Ao futuro nada mais pode oferecer que atenção e reverência." No entanto, o encontro com os jovens faz com que o futuro seja mais e mais aquele que imprime uma direção à escolaridade.

Mas a juventude envia a escola, que se encontra posta a seu serviço, ao futuro. [...] A exigência mais premente de toda a pedagogia moderna outra coisa não quer que criar espaço para a cultura que está surgindo. Ao confiar na juventude, que pouco a pouco há de aprender a trabalhar, a levar-se a sério e a educar-se, a humanidade confia em seu futuro. (Benjamin, 2007, p. 16)

A convocatória para enlaçar o passado com o presente e com o futuro, que é o que em definitivo "empurra" a proposta escolar, o leva a proclamar: "Basta de humanismo desbotado!". Cita uma "lista negra" de comentários de professores, que poderiam ser os mesmos que hoje encontramos em algumas classes.

...tanto faz se gostam ou não de Horácio; está no plano de estudos e temos que lê-lo;

Resposta de um professor a uma objeção contra uma argumentação de Cícero: "aqui na classe não queremos desenvolver nossas ideias, mas saber o que diz Cícero". "Ah, e não pense que acreditamos em seu entusiasmo pela Antiguidade", diz um professor a um aluno de Oberprima de um ginásio humanista. (Benjamin, 2007, p.42) ${ }^{3}$

Derrida, vem do grego arkheion, que significa uma casa, um domicílio, um endereço, a residência dos magistrados superiores, os arkhons, aqueles que mandam. Os documentos no arquivo, então, dizem a lei: "rememoram e invocam ou impõem a lei" (Derrida, 1996, p.2). Derrida segue dizendo que é nessa "domiciliação", nesse arresto domiciliar, que o arquivo ocorre. "O habitar, esse lugar onde habitam permanentemente, marca a passagem institucional do privado ao público, que nem sempre quer dizer do secreto ao não secreto" (p.3); o ato de guardar documentos também envolve ocultá-los. $\bigcirc$ direito que autoriza o arquivo e a lei na qual que se inscreve impõe limites, fronteiras, distinções, que podem ser desconstruídas se, como pretende Derrida, se pretende questionar a política do arquivo.

3. Algo semelhante diz Steiner: "compreendo perfeitamente a revolução contra os excessos no ensino secundário, comentários, análise e tudo isso". Porém, diante disso, diz sentir uma grande ambiguidade ou mesmo esquizofrenia: "Por outro lado, me assusta a ideia de perder 
Para Benjamin, esse humanismo desbotado deve reformular-se para dar lugar à "cultura juvenil" e para "encontrar um lugar para o presente na história da cultura" ( "O ensino da moral", de 1913; ver Benjamin, 2007, p.54). Essa ideia de "encontrar um lugar para o presente na história da cultura" é central para pensar tanto a renovação das humanidades como para fazer frente aos que só querem "presente" na escola, um presente entendido como as necessidades estreitas impostas pelo mercado.

\section{A TRANSMISSÃO CULTURAL SITIADA: ALGUMAS CHAVES GERAIS}

O segundo elemento que põe a transmissão cultural sob assédio é que há uma crise mais geral da noção de transmissão e de reprodução cultural (conceitos que não são equivalentes, mas que se referem à passagem um legado) ${ }^{5}$. No contexto de liquidez, de horizontes mais instáveis, a questão da reprodução cultural e política das sociedades se converte num problema. Como assinala Bauman (2002), o transitório e o curto prazo se tornam valores, e o perdurável, o longo prazo, o duradouro, gozam de má reputação. Como conseguir uma certa estabilidade na transmissão intergeracional capaz de assegurar a jovens a passagem da cultura de adultos? Como estabelecer certos pontos de referência se tanto os pontos de partida como os de chegada estão em permanente mudança e questionamento? Como evitar que essa transmissão não se interrompa com os deslocamentos (exílios, desemprego, mudanças, quebras) e turbulências a que está submetida hoje a vida de amplas camadas da população? (Reguillo, 2005). $\bigcirc$ antropólogo Arjun Appadurai, estudioso das transformações culturais de uma modernidade que "anda solta" e que não estava contida nas instituições que conhecíamos, assinala: "Enquanto as formas das culturas se tornam menos delimitadas e mais fluidas e politizadas, o trabalho da reprodução cultural se torna um trabalho diário mais arriscado" (Appadurai, 200 I, p.44).

essas referências essenciais que constituíram o substrato de nossa identidade. A identidade de uma língua, de um povo, de uma geração, está no seu legado, na herança que nos deixa daquilo que mais se apreciou do seu passado. Se isso se perde, corremos o risco de cair na barbárie de inovações ocas" (Steiner, Ladjali, 2005, p.93-94).

4. Claro que sua ideia da "cultura juvenil" não é a de certo populismo sociológico atual que celebra como autêntica e liberadora qualquer expressão dos jovens.

5. Veja-se Dussel (2007), para uma discussão sobre as voltas da transmissão e sua diferença em relação à ideia de repetição e clonagem. 
O risco o torna, também, mais difícil de prever e de estruturar. Gunther Kress, que trabalha com as novas alfabetizações, argumenta na mesma direção:

Num mundo de desestabilidade, a reprodução já não é um tema que preocupa: o que se requer agora é a habilidade para valorizar o que se necessita agora, nesta situação, para estas condições, estes propósitos, este público concreto, e tudo isso será configurado de forma diferente de como se configurará a tarefa seguinte. (2005, p.68-69)

psicanalista egípcio-francês Jacques Hassoun assinalava há mais de dez anos que os "velhos" (assim os chamava ele) já não têm quem escute suas histórias (Hassoun, 1996). Parece que estas já não interessam. Numa propaganda nos Estados Unidos se usava um bordão comum entre os ouvintes: It's so yesterday [é tão de ontem]. Se não a frase, ao menos o espírito pode ser encontrado na linguagem publicitária e no tom juvenil de boa parte da programação televisiva. Diz Monsiváis: "Com velocidade inconcebível em épocas anteriores, as referências se apagam ou se ajustam ao tamanho da fama televisiva, algo como: "Não há nada mais velho do que a informação cultural de meus pais" (2007, p.95).

Sobre esse fundo de crise da transmissão mais geral, a escola é rebaixada pelas próprias transformações, que colocam em dúvida sua própria legitimidade como instituição privilegiada de socialização (Dubet, 2004). Se antes constituía um espaço de transmissão cultural cuja cultura se distinguia claramente do afora e se sustentava numa aliança entre o Estado e as famílias, na atualidade a escola compete com outras agências culturais como os meios de comunicação de massas e a internet para a transmissão de saberes, a formação intelectual e a educação da sensibilidade das crianças e adolescentes. E compete em condições desvantajosas, já que por suas características "duras", por sua gramática estruturante, a escola se mostra menos permeável a essas novas configurações da fluidez e da incerteza.

Por sua vez, a escola se encontra com sujeitos bem diferentes daqueles a que estava acostumada e que esperava. As crianças hoje se sabem portadoras de direitos, discutem, argumentam e negociam a lei e a autoridade, e se comportam muitas vezes como consumidores precoces, clientes a quem se deve satisfazer antes que como cidadãos sujeitos à lei. Isso é importante lembrar 
diante das visões aistóricas e românticas de certas psicologias educativas, que naturalizam uma ideia de infância e deixam de lado as múltiplas inadequações geradas por essa horizontalização de posições. Sem ir muito longe, essa nova posição das crianças apresenta enormes desafios para a autoridade dos adultos na escola, o que se observa nas queixas reiteradas dos docentes sobre a dificuldade de "impor limites" ou de estruturar situações produtivas de ensino.

A transformação dos sujeitos não abarca apenas a infância. De acordo com alguns analistas (Lahire, 2004; Sloterdjik, 2005) estamos vivendo uma transição nas formas do individualismo que organizam a vida comunitária, e que as crianças e adolescentes de hoje põem isso em evidência. Enquanto no século XIX se priorizava a "busca do eu" interior, num olhar voltado para si mesmo, e o século $X X$ se mostrou como o século do narcisismo (Lasch, 1999), agora estamos passando a uma época do individualismo do autodesenho, do trabalho permanente e sustentável para converter a própria existência em um objeto estético original e criativo, uma recreação sem fim, em um movimento contínuo sobre si mesmo para desenvolver plenamente as próprias capacidades (Sloterdjik, 2005, p. I 5). Promove-se um trabalho ativo e prático dos indivíduos no desenho de suas vidas cotidianas, que já não se faz em nome de uma ética protestante do esforço, mas sim em prol dos prazeres e satisfações (Himanen, 2002). As ideias pedagógicas de autonomia, criatividade e independência, uma vez plenamente desenvolvidas correm o risco de nos converter em escravos de nossa autonomia (Walkderdine, 1995; Meurieu, 2002), de depositar sobre cada um de nossos ombros a tarefa e a responsabilidade de construir nosso sucesso ou, o que é mais provável, de suportar e explicar nosso fracasso. $\bigcirc$ individualismo do autodesenho se configura assim como um novo padrão que torna muito mais difícil estabelecer laços coletivos, formas de autoridade tradicionais e pautas de transmissão cultural mais estáveis e duradouras. Além disso, tem custos altos para os indivíduos, que, diante da dificuldade de sustentar esses ideais caem na depressão - que se revela como o sintoma da época - ou recorrem aos psicotrópicos e às terapias de todo tipo (Ehrenberger, 1999).

Nesse contexto, quais são os elementos que definem nossa vida em comum, isto é, os elementos culturais que agem como referência para todos? Monsiváis assinala que esses elementos em comum hoje vêm fornecidos sobretudo pela televisão. "A influência mítica da narrativa e da poesia se evaporou em boa medida, concentrando-se em alguns setores da cultura livresca". 
que antes era produzido por uma leitura escondida, hoje é propiciado por Star Wars, de outra maneira. "E a substituição proposta, a televisão, possui um efeito diferente, devastador a curto prazo, e carente do brilho do prestígio íntimo, não só por sua natureza, que consiste em acontecimentos efêmeros, como por sua massificação" (Monsiváis, 2007, p.94). Além de pouco íntimos e pouco "apropriáveis", esses encontros com a cultura comum se alteram todo o tempo: "a cada cinco ou dez anos se modifica e se redesenha o mapa das alusões compartilhadas" (Monsiváis, 2007, p.8I). Logo, são incompreensíveis para muitos e geram muitas dificuldades para conversas entre gerações, entre experiências distintas, entre "tribos", entre gostos. A tendência do indivíduo a se encerrar no bairro, na família, inclusive no próprio quarto, e conversar só com aqueles que "entende" ou com quem compartilha gostos, é uma consequência desse "medo ambiente" à alteridade, no dizer de Bauman (2002).

\section{A ESCOLA PODE ESCAPAR DO CERCO?}

Que lugar pode ser proposto então para a transmissão cultural na escola? O desafio é estruturar uma ideia de cultura comum que possa ser transmitida e compartilhada, que leve em conta as injustiças e privilégios do passado e que ao mesmo tempo proponha algumas outras inclusões que não venham da mão da cultura do mercado ou do indivíduo do autodesenho. Essa cultura comum teria que ajudar a aliviar o peso do individualismo, sem pretender com isso definir a transmissão cultural não importando quem está na frente. Nessa tensão entre universalização e individualização, se apresenta a possibilidade de uma cultura comum. Nos parágrafos que seguem, proponho alguns critérios gerais para repensar a transmissão cultural a partir da escola.

Em primeiro lugar, é preciso voltar a enfatizar que "ninguém é consciente do que é até se confrontar com a alteridade" (Steiner, Ladjali, 2005, p.37). A escola hoje, mais do que nunca, deve ser o lugar capaz de nos por em contato com um mundo-outro, porém, esse mundo-outro não é, necessariamente, o mundo tal como o concebiam as humanidades do século XIX, mas sim o mundo-outro que nos confronta com o desconhecido, o que nos permite entender e desafiar nossos limites e nos faz mais abertos aos outros e a nós mesmos. A escola, seja ensinando a linguagem, a história, a pintura, o cinema ou a computação, deveria poder nos ajudar a nos relacionar mais livremente 
com uma tradição, e, por isso mesmo, também deveria dar a essa tradição um lugar para que seja reescrita (Malosetti Costa, 2007). Como dizia Benjamin, a escola é passado, mas não é só passado; deve ser presente, porém, não apenas presente. Nesse cruzamento e rearticulação de temporalidades, pode haver lugar para uma transmissão que não seja apresentada como repetição mecânica de uma história, mas como a passagem de uma tradição que se renova e se redefine com cada nova geração.

Em segundo lugar, a escola deve sustentar-se na gratuidade do dom, sobre o que tanto falou Derrida em diferentes escritos. Gratuidade em múltiplos sentidos: porque é acessível a todos que queiram, mas sobretudo porque não exige ou promete que esse conhecimento vá ser utilitário, mas que servirá "para a eternidade" - como diz Lajonquière -, para outros tempos, para tempos que não têm forma no calendário social e sim no humano, o tempo de cada um. Além disso, a escola deve oferecer tempo, paciência, lentidão, silêncio, a possibilidade da dúvida (elementos mencionados por Steiner, Ladjali em seu Elogio da transmissão). Diante da aceleração dos tempos, da pressão da performance, da demanda de se reinventar e se autodesenhar todo o tempo, a escola pode oferecer um contexto onde se possa repousar "no outro", numa herança acumulada, num saber que o outro nos oferece, num espaço onde se possa errar e voltar a provar sem maiores consequências. Tudo isso é um dom a ser oferecido às novas gerações.

Em terceiro lugar, a escola deve dar mais chaves para decifrar a experiência comum, cada vez mais opaca em sua fragmentação e em sua velocidade de renovação (Martín-Barbero, 2006). Nessa tarefa, será importante recorrer às disciplinas para que nos forneçam modos de abordagem, linguagem, regras, que nos ajudem a construir alguma ordem e algum sentido ou interpretação, que construam uma distância (novamente a alteridade aparece como um tema), para que o indivíduo possa ser também indivíduo estranhando-se, sendo capaz de apor uma distância justa (comprometida, mas também mediada pela análise) entre o vivido e a construção de uma experiência. Mas também é necessário introduzir novos temas e novos modos de trabalho na escola ${ }^{6}$. Por exemplo, retomando um objeto que apareceu ao longo deste artigo,

6. Em outro texto (Dussel, 2006), ocupo-me em discutir a inclusão das novas alfabetizações. Remeto a ele para um desenvolvimento mais extenso dessa temática. 
não é tarefa menor começar a introduzir pautas e formas de trabalho com os meios que trazem outras ideias sobre o que fazer diante do que hoje está constituindo nossa "cultura comum". A "comunidade de espectadores" que cria o espetáculo midiático, que constrói uma "proximidade distante", ética e politicamente problemáticos, é uma das primeiras questões para interromper e questionar para que outra transmissão seja possível". "Não se deveria supor um 'nós' quando o tema é o olhar para a dor dos outros", diz Sontag (2003, p. I5). Como se forma esse "nós"? Que tipo de administração dos saberes e das paixões instala? Para uma analista francesa, Marie-José Mondzain, a violência dos meios reside precisamente na

...violação sistemática da distância. Essa violação resulta de estratégias espetaculares que embaralham, voluntariamente ou não, a distinção dos espaços e dos corpos para produzir um continuum confuso onde se apaga toda chance de alteridade. A violência da tela começa quando não é mais tela, por que já não é mais constituída como o plano de inscrição de uma visibilidade que espera um sentido". (2002, p.53-54)

Analisar os efeitos fusionais e confusionais das telas de televisão, a trama que "tecem invisivelmente entre os corpos que vêem e as imagens vistas", aquilo que "se representa na tela mas que não é visível nela" (Mondzain, 2002, p.52) deveria ser mais um elemento da transmissão cultural, capaz de habilitar melhor para recriar algo em comum. "Ver com outros, eis aí a questão, já que vemos sempre sozinhos e apenas compartilhamos aquilo que escapa à vista" (p.5I). Nesse aspecto, há um elemento importante que trabalha para o comum, que pode seguir tecendo e tramando uma sociedade onde nos importe o que acontece com o outro, seja este outro nosso aluno, nosso colega, nosso vizinho, nosso conhecido ou "o estrangeiro", e que nos importe o suficiente para demonstrar-Ihe nossa atenção, para esperar sua palavra, para superar a dificuldade de não entendê-lo e insistir no vínculo.

Finalmente, creio que é importante encontrar um modo de afirmação da transmissão cultural que não parta de um gesto amargo e desencantado.

7. Tema que o livro de Sontag (2003), Ante o dolor de los demás [Diante da dor dos outros, também traduzido e publicado no Brasil], aborda brilhantemente. 
Novamente remeto a Monsiváis (2007), que diz: "avento a seguinte hipótese: nestes anos, a tradição é aquilo que virá ou sucederá, não o ponto de partida" (p.36). Diante disso, a escola, essa depositária do passado que se encontra com o futuro nos jovens, deve evitar a nostalgia e sobretudo a amargura por não ser mais o centro das referências culturais. "Não há dor maior que a de ser proprietário de instrumentos subitamente descartados".

Quanto dos conteúdos escolares de hoje não reitera essa amargura, e se quer cobrar dos jovens essa dor?

Um filósofo espanhol, José Luis Pardo, fez uma apresentação maravilhosa sobre as relações entre pais e filhos e a transmissão intergeracional. Partindo da canção dos Beatles, She's leaving home, recria a discussão dos filhos nos anos 60, que abandonavam o lar para divertir-se, fazer amor e não a guerra, levar a imaginação ao poder, e cujos pais se sentiam traídos em seu sacrifício e em sua luta e trabalho duro para dar-lhes um futuro melhor. Ele compara essa cena com a cena atual, em que é difícil para muitos filhos sair de casa com medo do mundo, parecendo que os pais - esses filhos que foram embora de casa escutando Beatles - nada podem transmitir a não ser o desengano e a amargura, sem palavras diante da dor das guerras pois renunciaram a pensar sobre elas - e só podem balbuciar: "divirtam-se!", "tomem cuidado!". O que haveria mais para dizer? Permitam-me "roubar" de Pardo algumas ideias e emoções para pensar em outras transmissões para a escola. Ele apresenta uma carta hipotética de uma mãe para sua filha, que certamente em breve irá embora de casa:

Eu bem poderia dizer que minha vida não teve nenhum valor, que tudo foi em vão, que todas as coisas pelas quais me empenhei fracassaram, que meus semelhantes destruíram cada uma de minhas esperanças... isso eu poderia dizer se não tivesse ao menos uma vez visto uns olhos onde brilhava uma verdade distinta do massacre e da mesquinhez. E só esse instante valeu por toda minha vida e reduziu a pó todos os meus desenganos e decepções, me ensinou a rir com desprezo do sacrifício, da luta pela vida, do sagrado valor do trabalho e da humilhação ou exaltação da guerra, e me recordou o valor da felicidade. Esses olhos, querida, são os seus, com que me encontro agora, quando estou de volta,e que me lembram o que eu mesma buscava quando abandonei a casa de meus pais... Assim, se não lhe digo nada, ao menos quando nos cruzarmos no caminho, você na ida e eu na volta, se perceber em meus olhos um tremor insensato de felicidade e de esperança, um 
imperdoável desejo de deter a História e de declarar perdoadas todas as dívidas e enclausuradas todas as façanhas, não esqueça que foi você quem os iluminou com essa luz que busca aí fora; se a encontrar poderá fulminar com ela àqueles que querem fazê-la infeliz. (2007, p. I5)

Seria auspicioso que a transmissão cultural na escola se propusesse algum desses horizontes, que implicam retomar as melhores tradições do humanismo (quem, senão um humanista, buscaria nos olhos de outro humano as bases da esperança?), mas também conscientes de seu traumático legado. Essa "luz que pode fulminar àqueles que queiram fazer-nos infelizes" é talvez o melhor ensino que se poderia legar, ainda que custe ensiná-la, ainda que passe ou não passe pelas disciplinas escolares, ainda que saibamos que a escola não pode programá-la nem garanti-la ${ }^{8}$-, mas saibamos sim que pode ajudar a propiciar seu encontro e sustentá-la quando aparece.

\section{REFERÊNCIAS BIBLIOGRÁFICAS}

APPADURAI, A. La Modernidad desbordada. México: Fondo de Cultura Económica, 200I. BAUMAN, Z. La Modernidad líquida. Buenos Aires: Fondo de Cultura Económica, 2002. BENJAMIN, W. Obras. Madrid: Abada, 2007. Primeros trabajos de crítica de la educación y la cultura, libro 2, v. I.

BERGALA, A. La Hipótesis del cine: pequeño tratado sobre la transmisión del cine en la escuela y fuera de ella. Barcelona: Alertes, 2007

BOURDIEU, P.; PASSERON, J. C. La Reproducción. Barcelona: Laia, 1980.

DERRIDA, J. Aprender por fin a vivir: entrevista con Jean Birnbaum. Buenos Aires: Amorrortu, 2006.

Archive fever: a freudian impression. Chicago, London: The University of Chicago Press, 1996.

DEWEY, J. El niño y el programa escolar. Buenos Aires: Losada, 1967.

8. É expressão que usa Alain Bergala (2007) para falar da iniciação das crianças ao cinema, assinalando que a escola deve oferecê-la, mas deve saber que esse encontro não se controla com o planejamento nem tem garantias de êxito. 
DUBET, F. ¿Mutaciones institucionales y/o neoliberalismo? In: TENTI FANFANI. E. (ed.) Gobernabilidad de los sistemas educativos en América Latina. Buenos Aires: lipe-Unesco, 2004. p. 15-43.

DUSSEL, I. Curriculum, humanismo y democracia en la escuela media argentina ( I 863- | 920). Buenos Aires: Flacso, 1997.

De la primaria a la EGB: ¿Qué cambió en la enseñanza elemental en los últimos años? In: TERIGI, F. (comp.) Diez miradas sobre la escuela primaria hoy. Buenos Aires: Siglo XXI, Fundación OSDE, 2006. p.85-130.

A 30 años del golpe: repensar las políticas de transmisión en la escuela. In: RÍOS, G. (ed.) La Cita secreta: encuentros y desencuentros entre educación y memoria. Santa Fe: Amsafe, 2007. p. I57-178.

EHRENBERG, A. La Fatiga de ser uno mismo: depresión y sociedad. Buenos Aires: Nueva Visión, 1999.

FATTORE, N. Apuntes sobre la forma escolar "tradicional" y sus desplazamientos". In: BAQUERO, R.; DIKER, G.; FRIGERIO, G. (comp.) Las Formas de lo escolar. Buenos Aires: Del Estante, 2007. p. I3-32.

HASSOUN, J. Los Contrabandistas de la memoria. Buenos Aires: De la Flor, 1996.

HIMANEN, P. La Ética del hacker y el espíritu de la era de la información. Buenos Aires: Planeta, 2002.

HOBSBAWM, E.; RANGER, T. The Invention of tradition. Cambridge: Cambridge University Press, 1983.

HUNTER, I. Repensar la escuela. Barcelona: Pomares, 1998.

KRESS, G. El Alfabetismo en la era de los nuevos medios de comunicación. Granada: El Aljibe-Enseñanza Abierta de Andalucía, 2005.

LAHIRE, B. La Culture des individus: dissonances culturelles et distinction de soi. Paris: La Découverte, 2004.

LASCH, C. La Cultura del narcisismo. Barcelona: Andrés Bello, 1999.

MEIRIEU, P. Le Pédagogue et les droits de l'enfant: histoire d'un malentendu? Condé-surNoireau: Éditions du Tricorne, 2002.

MALOSETTI COSTA, L. Tradición, familia, desocupación. In: SEMINARIO INTERNACIONAL EDUCAR LAMIRADA: EXPERIENCIAS EN PEDAGOGÍAS DE LA IMAGEN. Anais... Buenos Aires: Flacso/Argentina; Fundación Osde, 2007. 
MARTÍN-BARBERO, J. Nuevas visibilidades políticas de la ciudad y visualidades narrativas de la violencia. Revista de Crítica Cultural, n.3, 2006.

MONDZAIN, M. J. L'Image, peut-elle tuer? Paris: Bayard, 2002.

MONSIVÁIS, C. Las Alusiones perdidas. México: Anagrama, 2007.

PARDO, J. L. Mother \& child reunion. In: SIMPOSIO ENCUENTROS ENTRE GENERACIONES. Anais... Barcelona, 2007.

REGUILLO, R. Horizontes fragmentados: comunicación, cultura, pospolítica. El (des)orden global y sus figuras. Guadalajara: Iteso, 2005.

SLOTERDIJK, P. Sobre la mejora de la buena nueva: el "quinto" evangelio según Nietzsche. Madrid: Siruela, 2005.

SONTAG, S. Ante el dolor de los demás. Buenos Aires: Alfaguara, 2003.

STEINER, G.; LADJALI, C. Elogio de la transmisión. Madrid: Siruela, 2005.

WALKERDINE, V. Psicología del desarrollo y pedagogía centrada en el niño: la iserción de Piaget en la educación temprana. In: LARROSA, J. et al. Escuela, poder e subjetivación. Madrid: La Piqueta, 1995.

WILLIAMS, R. Culture and society, I780-1950. London, New York: Columbia University Press, 1958.

Recebido em: agosto 2008

Aprovado para publicação em: agosto 2008 